\title{
Furthering Studies or Opting For a Career: Any Role for EFL Students' Emotional Intelligence?
}

\author{
Fatemeh Shahhoseini \\ M. A. in Teaching English \\ Alzahra University of Tehran, Iran \\ Mohammad Savari Katuli \\ M. A. in Computer Engineering \\ Mirdamad University of Gorgan
}

\begin{abstract}
Within the literature on emotional intelligence (EI), no studies have yet looked into the hypothesis that EFL students' EI can contribute to their decision on furthering their studies to get the Ph.D. degree or alternatively entering the job market, destined for a career. Bearing on the point that emotional intelligence helps people manage the stress and emotions facing difficult situations, achieve higher levels of self-awareness and, in consequence, greater success in life, the present work aimed at documenting how EFL masters students' emotional intelligence quotient (EQ) relates to their decision about the future. To this aim, 120 M.A. students of TEFL from three different public universities were asked to answer the Bar-on EQ questionnaire along with 12 open-ended questions intending to explore choices they make for their future. Interestingly, content analysis of the open-ended questions revealed that EFL learners' EQ does not have a part in their decisions about the future. Among other findings, it was also intriguing to find that irrespective of their emotional intelligence, most of the students, gave a high priority to building a better career. Financial issues were the main logic behind leaving university to follow job opportunities after getting their Masters.
\end{abstract}

\section{INTRODUCTION}

EQ is the ability of people in perception and recognition and it shows that how much people can manage their emotions and their excitements. EQ shows that we can understand other emotions. It is proved that people who can recognize their emotion and other people's emotions will be more successful in their life and also in their works. ${ }^{[1]}$ Meyer and Salovey (1997) believed that, one of the main benefits of regulating emotions is that if we regulate our emotions, then we can eliminate negative emotions and improve them to some extent. In fact, if we learn how to regulate our emotions, then we can be able to manage our negative emotions and change them into positiveones by using pleasant tasks and activities that change the mood into positive feelings ${ }^{[1]}$ Actually, there should be an adoption between emotion and Emotional Intelligence makes this adoption possible and this in turn will result in adoptive action. ${ }^{[2]}$

One of the problems students encounter after graduating from MA is their future. It seems that there are several different ideas about this issue among students. The aim of this study is to investigate any relationship between EQ of students and their desire for following their education to the higher level that is PHD. The level of EQ shows how much a person is able to control the emotions in different situations and it is predicted that this may be a factor in making decision for the future. As it is widespread, there are heavy works in MA on the shoulders of students and due to these heavy responsibilities they may give up following education and start finding a job.

\section{Literature REVIEW}

\section{Intelligence}

Intelligence has different definitions in different times, Binet in 1905defined it as one dimensional concept, Gardner in 1983defined it as a multiple concept and Salovey and Mayer in 1990considered it as an emotional notion. ${ }^{[3][4][5]}$ 
On the other hand emotional intelligence (EI) is defined as a trait "an array of emotional and social abilities, competencies and skills that enable individuals to cope with daily demands and be more effective in their personal and social life." ${ }^{,[6]}$

Intelligence test was designed by Alfred Binet in 1900 for the first time to determine the children who develop slower that the other students in class. ${ }^{[7]}$

\section{Emotional Intelligence}

\section{Background}

The term Emotional Intelligence is an old idea. As Aristotle in ancient times believed that educating the mind should be accompanied with educating the heart unless it worth nothing. ${ }^{[8]}$ Kristjansson, (2007) mentioned that according to Aristotle humans are social and emotional animals and if we extend this concept, they are emotional and social learners. ${ }^{[8]}$ Although some believe that this usage of emotion and emphasis on personal and social contributions to intelligent behavior complements the old view of intelligence, but by the former citations the history and importance of Emotional Intelligence become clear. ${ }^{[9]}$ It is clear from the literature of emotional intelligence that this term is not a new term but it was used from the Aristotle time and from that time scholars have regarded it as an important concept in the process of learning.

\section{Definitions}

Goleman defined emotional intelligence as including "abilities such as being able to motivate oneself and persist in the face of frustration, to control impulses and delay gratification; to regulate one's moods and keep distress from swamping the ability to think; to emphasize and to hope." [10]

The concept of EI is in line with social intelligence so that in 1920s Thorndike considered EI as social intelligence. It was emerged from his studies that EI can be side with others and rational in relationships. ${ }^{[11]}$ But his viewpoint about EI was not regarded so much for many years. Interestingly, Howard Gardner's ideas about EI was in line with Thorndike. ${ }^{[11]}$ On the other hand, Gardner proposed the theory of "multiple intelligences" and a model including eight different types of intelligence was presented by him. ${ }^{[12]}$

Salvoy and Meyers in the early 1990s defined the Emotional Intelligence for the first time as "a type of social intelligence that involves the ability to monitor one's own and others' emotions, to discriminate among them, and to use this information to guide one's thinking and actions." ${ }^{[13]}$ Mayer and Salovey (1997) also defined Emotional Intelligence as the ability to express, recognize and apply excitements and the way of managing it. ${ }^{[1]}$

Bar-On (1998) coined the term EQ for the first time as a correspondent to IQ. In his opinion, EQ is a collection of some necessary abilities for social life including emotional and social. Bar-on (1997) identified EI as "an array of noncognitive capabilities, competencies, and skills that influence one's ability to succeed in coping with environmental demands and pressures" His model of EI is consisted of five broad areas of skills or competencies: intrapersonal EQ, interpersonal EQ, adaptability EQ, stress management EQ, and general mood EQ. ${ }^{[14]}$ Eventually, the idea was presented into the world by publication of Daniel Goleman's best-seller book entitled "Emotional Intelligence" in 1995 (p. 14).

\section{The importance of emotional intelligence}

Nowadays the focus of most of the researchers is on social and psychological factors that makes individual differences among learners. ${ }^{[16]}$ In the field of educational psychology, one of the important concepts is Emotional Intelligence. In 1990 as the concept of research became important, the focus grew on the importance of the interaction between thought and emotion. ${ }^{[17]}$ Despite the fact that society regarded the academic intelligence as the most important factor, Bar-on (1997) believed that emotional and social intelligence are crucial factors that predict the future success. ${ }^{[8]}$

Some researchers believe that emotional intelligence is a new concept and there have not done enough research regarding the effect of EI on learning. ${ }^{[18]}{ }^{[19]}$ But recently, there are some researches regarding this issue in relation with academic achievement. For example Pishghadam, 2008 proved the strong relationship between EI and achievement in academic life. ${ }^{[20]}$ Motallebzadeh \& Azizi (2012) in their study, found a positive relationship between EQ and in another study, Moafian\& Ghanizadeh (2009), found out the significant relationship between teacher's EI and self-efficiency. ${ }^{[21]}$ 
Zarezadeh, (2013) based on the result of her study claimed that On the basis of emotional intelligence affects English language learning positively. ${ }^{[22]}$ And there are many other studies like this that shows the importance of EQ in relation to other elements of learning or education in general. Investigating different studies proved by scholars that emotional intelligence is a determining factor in many areas of education.

\section{Significance of this study}

Within the literature on emotional intelligence (EI), we can claim that no studies have yet investigated the hypothesis that EFL students' EI can contribute to their decision on furthering their studies to get the Ph.D. degree or alternatively entering the job market, destined for a career.

\section{Methodology}

\subsection{Participants}

Participants of this study were 120 M.A. students of TEFL, 47 male and 73female, from 3 different universities in Iran, from different cities; they were 45 students from Alzahra University of Tehran, 39 students from GuilanUniversity and 36 students from Azad University of Gorgan. Most of them were passing their last semester and their major were both English literature and teaching English as a foreign language.

\subsection{Instrument}

In this study, two instruments were used for the purpose of collecting quantitative data. The first one was Emotional Intelligence Test also called Emotional Quotient Inventory (EQ-i; Bar-On, 1997) which was developed by Bar-On (1997) which reliability and validity of this test is measured by Darek and Hart. (2000); the test is a self-report measure of emotionally and socially intelligent behavior which contains 90 items in the form of short sentences. It applies Likert scale with a textual response format ranging from "totally agree to totally disagree" options which contains five numbers $(1,2,3,4$, and 5) each level separately. The second instrument utilized in this study was 12 openended questions developed by the researchers, intending to explore choices they make for their future.Participants took this questionnaire named job or education, included 12 short questions that requires explanatory answers to clarify their attitude toward education following and finding job and giving education up to a great extent.

\subsection{Procedure}

As the first step, the reliability of the second questionnaire that was developed by the researchers was measured. It was administered to 100 students of Giti language institute of Gorgan and by using Cronbach alpha coefficient, the reliability coefficient was calculated as 0.74 which is an acceptable reliability coefficient.

After establishing the reliability of the test, in order to estimate the emotional intelligence of subjects, the researchers administered it in the academic term. Students were told they were going to answer questions about their emotional intelligence and also about job or education in the future after graduating, and that the questions had no right or wrong answers. The questionnaire had no ambiguity, but the students could freely ask any questions they might have had. The administration of the two tests took 20 to 25 minutes.

\section{Data Analysis}

The students were divided into Two groups based on their emotional intelligence scores, students with high EQ scores (or high group) and students with low EQ scores (or low group). In this study, 57 students were regarded as emotionally less intelligent (low group) and 63 students were considered as emotionally more intelligent (high group).

The EQ test that was used has 96 items and the whole score of this test were 453, the people who receive above 270 are people with high level EQ, and the people who get below that point, are low level EQ.

The answers of these two groups to the questions regarding their desire to follow their education in the future were relatively the same. In the questionnaire named job or education, questions 3 were related to the desire of following education. From the high EQ students that were 21, about 18 of them were interested in following their education in every situation and they believe that having higher 
education will cause better chance for them to find a job. From that 18, about 10 of them were more eager to follow the education regardless of the impact of education on finding a better job, and the financial problems were not important for them. From the low EQ students who were about 18 people, about 14 of them were eager to follow their education due to their answer to $3^{\text {rd }}$ question of the think aloud protocol.

The difference were seen is that the people who are interested to give up education and find a job from low EQ, mentioned financial problems as one of the major barriers for them, but the 3 people who were not eager to follow education from high EQ students were not mentioned that. They do not agree the big importance of financial issues, just they mentioned that social importance of having a good job and they believe that having higher education degrees does not guarantee a better job.

In question 10, the choice between higher education and good job value is proposed. The answer of different EQ levels were not gives me a pattern that which group has a fix idea. Some high EQ level students (about 10) believed that education is more important and asserted it directly, but the rest (about 11), believed that they are complementary issues and mentioned that both are important. On the other hand, from 18 of the students who are in low EQ level, 10 of them believed that education is more essential in our country, and the rest of them believed that both are equally important.

\section{CONClusion}

As the data in analysis part showed, there is not any significant difference between the high level EQ and low level EQ students in terms of their decision about their future. The number of students that were chosen to follow their education in both groups was almost equal and also the number of students who were interested in giving education up and finding a related job in both groups were almost the same. Therefore it can be concluded that EQ is not an important factor in decision that MA students make about their future.

I think the result of this study maybe true but because of the number of participants that were not enough, I doubt that maybe the result is due to the number of students and if we have 100 participants, the result may vary.

Another thing that worth mentioning is that I believe that attitude of male and female if be separated is better. The separation of male and female I think will result in better results and better and narrower conclusion for the future studies. If replicated on a larger scale, this finding gives insights into an unexplored aspect of the literature on emotional intelligence.

\section{ACKNOWLEDGMENT}

Grateful thanks specially to the manager of Giti language Institute, the teachers and the students who are involved in this project.

\section{REFERENCES}

[1] Madahi Mohammad Ebrahim, javidi Nasirudin, Samadzadeh Mona. (2013). The relationship between emotional intelligence and marital status in sample of college students. Procedia - Social and Behavioral Sciences 84, 1317 - 1320.

[2] Shutte, N. C., Malnuff, J. M., Thorsteinsson, E. B., Bhullar, N., \& Rooke, S. E. (2007). A metaanalytic investigation of the relationship between emotional intelligence and health. Personality and Individual Differences, 42, 921-933.

[3] Binet, A. (1905). A propos la mesure de l' intelligence. L' Annee Psychol., 2, 411-465.

[4] Gardner, H. (1983). Frames of Mind: The Theory of Multiple Intelligence. New York: Basic Books.

[5] Mayer, J. D., \& Salovey, P. (1990). Emotional intelligence. Imagination, Cognition and Personality, 9 (3), 185-211

[6] Bar-On, R., Tranel, D., Denburg, N. L., \& Bechara, A. (2003). Exploring the neurological substrate of emotional and social intelligence. Brain, 126, 1790-1800.

[7] Minton, H.L. (1998). Commentary on: 'New methods for the diagnosis of the intellectual level of subnormals' Alfred Binet \& Theodore Simon (1905); 'The uses of intelligence tests' Lewis M. Terman (1916). Classics in the History of Psychology. Retrieved on 20 September from http://psychclassics.yorku.ca/Binet/commentary.htm 
[8] Pishghadam, R. (2009). A Quantitative Analysis of the Relationship between Emotional Intelligence and Foreign Language Learning. Electronic Journal of Foreign Language Teaching, 6, 31-41.

[9] Darek Dawda, Stephen D. Hart. (2000). Assessing emotional intelligence: reliability and validity of the Bar-On Emotional Quotient Inventory (EQ-i) in university students. Personality and Individual Di€erences 28, 797-812.

[10] Goleman, D. (1995). Emotional intelligence. NY, NY: Bantam Books.

[11] Goleman, D. (1998). Working with emotional intelligence. New York: Bantam

[12] Mayer, J.D,\& Salovey, P. (1997). What is emotional intelligence? In P. Salovey, \& D. Sluyter (Eds), Emotional development and emotional intelligence: Educational implications. New York: Basic Books.

[13] Bora, F. D. (2012). The impact of emotional intelligence on developing speaking skills: From brain-based perspective. Procedia - Social and Behavioral Sciences 46 , 2094 - 2098

[14] Bar-On, R. (1997). Bar-On Emotional Quotient Inventory: User's manual. Toronto: Multi-Health Systems

[15] Goleman D. (1995) Emotional intelligence, Random House Inc., New York

[16] Meysam Zafari, Reza Biria. (2014). The Relationship between Emotional Intelligence and Language Learning Strategy Use. Procedia - Social and Behavioral Sciences 98, 1966 - 1974.

[17] Mayer, J.D., Salovey, P., \& Caruso, D.R. (2000). Models of emotional intelligence. In R.J. Sternberg (ed.): Handbook of Intelligence (2nd ed) (pp. 396-420). New York: Cambridge

[18] Ghosn, Irmak (2000): "Nurturing emotional intelligence through literature". Forum 39/1: 1-10

[19] Pishghadam, R. (2008): "On the influence of emotional and verbal intelligence on second language learning. Teaching". Electronic Journal of Foreign Language 2009, Vol. 6, No. 1, pp. $31-41$

[20] Moafian, F. \& Ghanizadeh, A (2009): The relationship between Iranian EFL teachers' emotional intelligence and their self-efficacy in Language Institutes. Volume 37, Issue 4, December 2009, Pages 708-718

[21] Jamali Nesari A, Karimi L, Filinezhad N. (2011). On the Relationship between Emotional Intelligence and Vocabulary Learning of Iranian EFL Learners at the Intermediate level. Procedia - Social and Behavioral Sciences 28, 900-903.

[22] Zarezadeh, T. The effect of emotional intelligence in English language learning, Procedia Social and Behavioral Sciences 84, 1286 - 1289 (2013).

\section{AUTHORS' BIOGRAPHY}

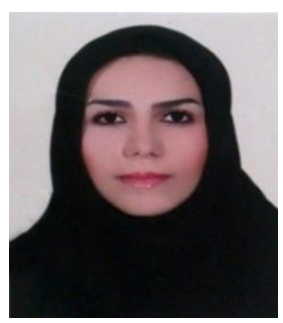

Fatemeh Shahhoseini, is graduated M.A. student of TEFL, University of Alzahra, and Tehran, Iran. Her fields of interests include Computer Assisted Language Learning, Mobile Assisted Language Learning, Learning Strategies, and more specifically the area which deals with Emotional Intelligence, Critical Thinking and Reading Motivation. She has actively participated in several national and international conferences on TEFL, which has led to publishing a number of seminal papers.

Mohammad SavariKatuli M.A, student of Computer Engineering at Mirdamad University of Gorgan,got Bachlor of engineering in Information Technology from Applied Science University of Gorgan in 2013.apart from his own major he is interested in English Teaching and learning and different issues around this area. 